\title{
A resampling-based meta-analysis for detection of differential gene expression in breast cancer Bala Gur-Dedeoglu ${ }^{\dagger 1}$, Ozlen Konu ${ }^{\dagger 1}$, Serkan Kir ${ }^{1}$, Ahmet Rasit Ozturk ${ }^{1}$, Betul Bozkurt ${ }^{2}$, Gulusan Ergul ${ }^{3}$ and Isik G Yulug*1
}

\begin{abstract}
Address: ${ }^{1}$ Department of Molecular Biology and Genetics, Faculty of Science, Bilkent University, TR-06800, Ankara, Turkey, ${ }^{2}$ Department of General Surgery, Ankara Numune Research and Teaching Hospital, TR-06100, Ankara, Turkey and ${ }^{3}$ Department of Pathology, Ankara Numune Research and Teaching Hospital, TR-06100, Ankara, Turkey

Email: Bala Gur-Dedeoglu - bala@fen.bilkent.edu.tr; Ozlen Konu - konu@fen.bilkent.edu.tr; Serkan Kir - serkankir@gmail.com; Ahmet Rasit Ozturk - ahmetrasit@bilkent.edu.tr; Betul Bozkurt - b2bozkurt@yahoo.com; Gulusan Ergul - gulusanergul@yahoo.com; Isik G Yulug* - yulug@fen.bilkent.edu.tr

* Corresponding author †Equal contributors
\end{abstract}

Published: 30 December 2008

BMC Cancer 2008, 8:396 doi:10.1 |86/147|-2407-8-396
Received: 21 May 2008

Accepted: 30 December 2008

This article is available from: http://www.biomedcentral.com/I47I-2407/8/396

(c) 2008 Gur-Dedeoglu et al; licensee BioMed Central Ltd.

This is an Open Access article distributed under the terms of the Creative Commons Attribution License (http://creativecommons.org/licenses/by/2.0), which permits unrestricted use, distribution, and reproduction in any medium, provided the original work is properly cited.

\begin{abstract}
Background: Accuracy in the diagnosis of breast cancer and classification of cancer subtypes has improved over the years with the development of well-established immunohistopathological criteria. More recently, diagnostic gene-sets at the mRNA expression level have been tested as better predictors of disease state. However, breast cancer is heterogeneous in nature; thus extraction of differentially expressed gene-sets that stably distinguish normal tissue from various pathologies poses challenges. Meta-analysis of high-throughput expression data using a collection of statistical methodologies leads to the identification of robust tumor gene expression signatures.
\end{abstract}

Methods: A resampling-based meta-analysis strategy, which involves the use of resampling and application of distribution statistics in combination to assess the degree of significance in differential expression between sample classes, was developed. Two independent microarray datasets that contain normal breast, invasive ductal carcinoma (IDC), and invasive lobular carcinoma (ILC) samples were used for the meta-analysis. Expression of the genes, selected from the gene list for classification of normal breast samples and breast tumors encompassing both the ILC and IDC subtypes were tested on 10 independent primary IDC samples and matched non-tumor controls by real-time qRT-PCR. Other existing breast cancer microarray datasets were used in support of the resampling-based meta-analysis.

Results: The two independent microarray studies were found to be comparable, although differing in their experimental methodologies (Pearson correlation coefficient, $R=0.9389$ and $R=0.8465$ for ductal and lobular samples, respectively). The resampling-based meta-analysis has led to the identification of a highly stable set of genes for classification of normal breast samples and breast tumors encompassing both the ILC and IDC subtypes. The expression results of the selected genes obtained through real-time qRT-PCR supported the meta-analysis results.

Conclusion: The proposed meta-analysis approach has the ability to detect a set of differentially expressed genes with the least amount of within-group variability, thus providing highly stable gene lists for class prediction. Increased statistical power and stringent filtering criteria used in the present study also make identification of novel candidate genes possible and may provide further insight to improve our understanding of breast cancer development. 


\section{Background}

Microarray studies aiming to identify differentially expressed as well as co-regulated gene sets and signaling pathways involved in different cellular states have greatly improved our understanding of breast cancer at the molecular level. The power of expression profiling using cDNA or DNA microarrays for distinguishing subgroups of breast cancers has been demonstrated by several groups [1-4].

The identification of an intrinsic gene-set exhibiting high variability among different tumor clusters has been informative in describing different subtypes of breast cancer samples. However, only a few papers have been published on gene expression profiles of normal cell populations in breast tissue [5-9]. Therefore, it is of paramount importance for the research community in the field of tumor biology to have access to gene lists that exhibit low variability in expression among tumors and yet are distinguishable from a normal tissue profile.

Meta-analysis of microarray datasets has the potential to lead to more comprehensive measures of the existing differential gene expression data and can therefore provide gene sets with a high diagnostic value. Meta-analysis of independent microarray datasets generated with the common objective of identifying differentially expressed genes in a certain type of cancer has also been performed for breast cancer. In a very recent meta-analysis study, Smith et al. identified differentially expressed genes between ER+ and ER- breast tumors by gathering 9 independent breast cancer microarray studies [10]. Another study used the power of meta-analysis to find out the relation of expression patterns of gene and chromosomal positions. More than 1200 breast tumors were collected from eight independent breast studies and candidate metastasis suppressor and promoting genes were found from a given set of chromosomal regions [11]. Similarly, Hu et al. were able to identify a new intrinsic gene-set for breast cancer subtype prediction by combining multiple microarray datasets to assess prognosis [12].

Several different meta-analysis approaches exist in the literature. In some, each individual study contributes rather independently to the meta-analysis [13-15] whereas in others the values are treated as members of a single study thus requiring a generalized normalization step $[16,17]$. Direct comparison of gene expression values from multiple studies may be relatively more problematic than comparing the effect size obtained from individual studies. Yet, analysis of combined raw data is beneficial when sample sizes of individual studies are small. Another important concern in meta-analysis is the determination of the minimum number of samples required to obtain statistically reliable results [18]. One possible solution to this problem is resampling; for example, one can use a delete-d-jacknife procedure in which a subset of data is excluded to find out the frequency of selecting a particular gene as differentially expressed [18]. The number of replicates required for producing stable differentially expressed gene lists could also be determined based on a related method known as leave-one-out resampling [19].

Existing meta-analytic approaches applied to different types of cancer show the power of a combined study for identifying novel genes not present in the existing literature (e.g., liver cancers) $[20,21]$. Invasive ductal carcinoma (IDC) and invasive lobular carcinoma (ILC) make up to $95 \%$ of all breast tumors (IDC: $50-80 \%$ and ILC: $10-15 \%)[2,22-24]$. Although recent studies suggest differences between the expression profiles of IDC and ILC, the clinical progress, therapeutic response, and molecular signature, there are also many similarities between IDC and ILC tumors distinguishing them from normal breast tissue $[2,5,23,25]$. However, meta-analysis of gene expression differences between normal breast tissue and such a generalized set of breast tumors has not been reported to date.

In the present study, we primarily aimed to develop a novel methodology for the meta-analysis of independent microarray datasets. Using this methodology, we provide gene lists that (a) are discriminative of breast cancer types (IDC, ILC) and normal breast cell populations, (b) may yield breast tumor markers that are invariably expressed across independent experiments, and (c) provide a set of consistently differentially expressed gene candidates with potential discriminative ability for tumor subtypes. Using a method similar to delete-d-jacknife, a series of $d$ sample size values have been tested to assess the extent of variability across the tumor samples and the stability of differential expression. Comparison of probability value distributions obtained for the test and randomized samples has led to determination of the degree of differential expression between groups tested. Accordingly, we report that the Sorlie et al. [1] and Zhao et al. [2] datasets were highly comparable. Our resampling-based meta-analysis led to the identification of genes not differentially expressed when analyzed independently. Predictive ability of the meta-gene set was independently supported in three other breast cancer microarray studies with information on breast normal and tumor tissues $[5,7,8]$ using BRB-TOOLS [26]. A subset of the meta-gene-list was also used as a classifier to accurately predict different molecular subtypes, such as luminal/basal and ER+/ER- based on microarray datasets in which patient subtype classification was available $[7,8]$. Moreover, selected candidates from stable gene sets obtained from the meta-analysis were validated by real-time qRT PCR. Use of resamplingbased meta-analysis combined with class prediction via 
available microarray datasets pointed to the existence of a tumor-specific differentially expressed gene-set with predictive potential for tumor subtype classification.

\section{Methods}

\section{Data retrieval for resampling-based meta-analysis}

Two independent microarray gene expression data sets, Sorlie et al. [1] and Zhao et al. [2], were downloaded from the Stanford Microarray Database (SMD); http://genomewww5.stanford.edu/[27]. Gene filtering options of SMD were used for log transformation and median centering the data arraywise. Expression values that were missing in more than $20 \%$ of the data were excluded from the analysis. Details of tumor specimen histology, available on SMD, were used to restructure the experiments according to breast tumor subtypes as invasive ductal carcinoma (IDC), invasive lobular carcinoma (ILC) and normal samples. Datasets were combined with respect to probe IDs using a set of customized perl routines (source codes are available upon request). These two data sets combined resulted in an initial list of 4769 IMAGE clones (3465 unique genes) common in both datasets (see Additional file 1; Zhao dataset and Additional file 2; Sorlie dataset). A total of 139 IDC (38 samples Zhao, 101 samples Sorlie datasets), 29 (21 samples Zhao, 8 samples Sorlie datasets) ILC and 7 (3 samples Zhao, 4 samples Sorlie datasets) normal samples were available for further analysis.

\section{Data Filtering}

Data were filtered separately for ductal and lobular samples. IMAGE clones with more than $50 \%$ missing data in either of the Sorlie or Zhao datasets were excluded from the common clone set. Data filtering was further improved by performing two-tailed Student's t-tests with equal variance $\left(\mathrm{Matlab}^{\circledast}\right.$ ) between the Sorlie and Zhao datasets for the IDC and ILC samples separately. Those clones with probability values less than 0.05 (after Bonferroni correction) were excluded from further analysis. This two-step data filtering resulted in a common set of 1726 IMAGE clones for the analysis of ductal and normal samples, and 2029 IMAGE clones for the analysis of lobular and normal samples. Upon taking the intersection of the ductal-normal and lobular-normal clone sets, 1522 IMAGE clones were available for the ductal-lobular analysis. The resulting clone subsets were further filtered by removing IMAGE clones with more than $40 \%$ missing data for the two groups in comparison (e.g., ductal and normal) in the combined data before application of the resampling steps. In addition, if an IMAGE clone had a sample size (of normal samples) less than the resampling sample size, data on this IMAGE clone was also removed.

\section{Resampling and statistical analysis}

We have used a resampling method for meta-analysis of microarray data in which the significance of the differ- ence between group medians (e.g. ductal vs. lobular) could be tested upon a series of resampling schemes from the original and multiple randomly shuffled datasets (Figure 1; code written in Matlab ${ }^{\circledast}$ using Statistics Toolbox is available upon request). Accordingly, a preset number of samples was selected from each group (i.e., IDC, ILC, normal) of the original dataset, referred herein as the test. The p-value was calculated indicating the significance of the difference between the group medians based on the Wilcoxon Rank Sum Test. This test was repeated for a series of $i$ number of iterations; at the end of each iteration scheme, a set of $p$-values ( $p t$ ) per IMAGE clone was obtained. The above procedure was also applied to each of the shuffled datasets yielding pr1 and $p r 2$. P-value distributions were then tested in a pair-wise fashion (i.e., $p t$ vs. $p r 1$; and $p r 1$ vs. pr2) using the twosample Kolmogorov-Smirnov test for each clone in the dataset (Figure 1). The resulting p-values were named as $k s t$ and $k s r$, respectively. To obtain an estimate of the false discovery rate (FDR), $k s r$ values were sorted in the ascending order and the $k^{\text {th }}$ value from the top (lowest pvalue) was determined as $\mathrm{FDR}_{\text {observed, }}$, where $k$ equals the expected value of FDR (e.g., 0.01) multiplied by the number of IMAGE clones tested. FDR observed $_{\text {was set }}$ the threshold according to which IMAGE clones were assigned as significant or not. If kst of a particular gene had a value that was smaller than the $\mathrm{FDR}_{\text {observed }}$ the gene was accepted to be significant.

\section{Application to the breast cancer datasets}

The above tasks were performed for a particular sample size $n$ (e.g., 3), repetitively for $i$ number of times where $i=10,20,30, \ldots, 100$ and 150 . For each particular $i$, three parameters were recorded, namely, kst values, the mean expression value of each of the two groups compared, and the significance of the differential expression based on kst and $k s r$. These above steps were then repeated with different sample sizes: For ductal vs. lobular comparison, $n$ was set to be $3,4,5,6,10,15$ and 20 . On the other hand, since the total number of normal samples was 7 , the highest sampling value could be set to 6 for ductal vs. normal and lobular vs. normal comparisons, and $n$ equaled 3, 4, 5 and 6 . These sample size-iteration combinations led to 77 runs for ductal vs. lobular analysis, and 44 runs for ductal vs. normal and lobular vs. normal analyses. At the end, a final differentially expressed gene set was determined for each of the three comparisons (i.e., ductal vs. lobular, DL; ductal vs. normal, DN; lobular vs. normal, LN) by gathering the IMAGE clones that were assigned as significant in $90 \%$ or more of these 44 or 77 runs. The mean values of each of the two groups in comparison obtained at $n$ $=20$ (or 6, in the case of normal vs. tumor comparisons) and $i=150$ were used as an estimate of the measure of expression. 


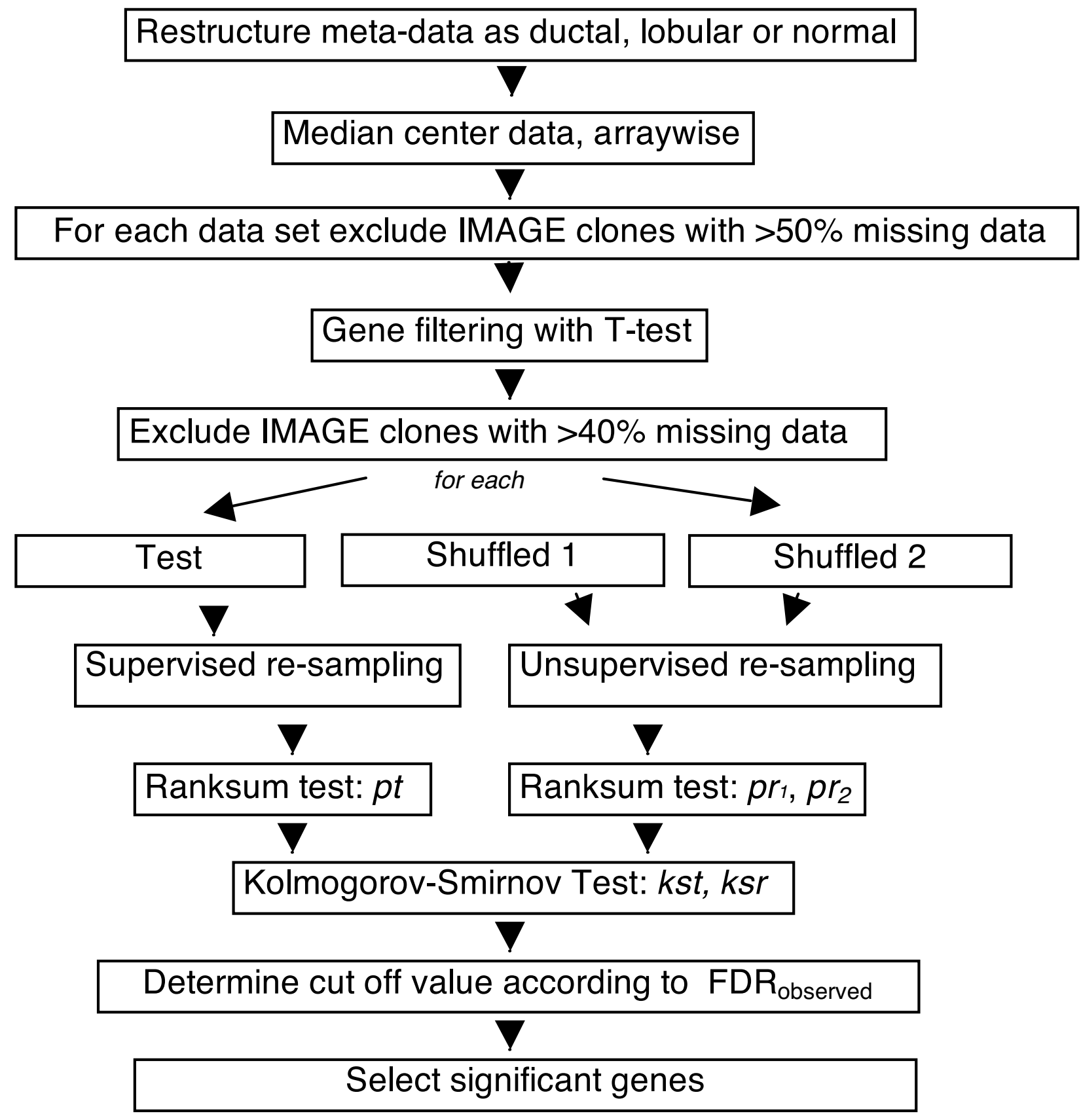

Figure I

General meta-analysis scheme. Workflow is represented by boxes and arrows.

\section{Data retrieval and analysis for validation studies}

The ".cel files" of the three publicly available independent microarray gene expression data sets, GDS2635 [5], GDS2250 [7] and GDS1329 [4], were downloaded from GEO [28] and processed by the BRB-ARRAYTOOLS [26]. All three datasets were obtained using the Affymetrix HGU133A or HGU133 Plus 2.0 platform; thus they were highly comparable. In GDS2635 the aim was to identify gene expression profiles of microdissected ductal and lobular carcinomas in relation to their normal ductal and lobular cells $(\mathrm{n}=10)$. The authors identified multiple genes differentially expressed in comparisons between ductal and lobular tumor and normal cells [5]. In the GDS2250 study, a gene expression array-based analysis of 
three breast tumor subtypes, i.e., sporadic basal-like cancer (BLC), BRCA-associated breast cancer, and non-BLC, was performed. They used 47 human breast tumor cases to provide insight into the molecular pathogenesis of BLC and BRCA1-associated breast cancer and the contribution of $\mathrm{X}$ chromosome abnormalities to the pathogenesis of BLC [7]. In GDS1329, Farmer et al. performed an analysis of tumors from 49 breast cancer patients that were successfully classified into luminal and basal classes, and a novel molecular apocrine class. Apocrine tumors were estrogen receptor negative ER(-) and androgen receptor positive $\operatorname{AR}(+)$, while luminal tumors were $\mathrm{ER}(+)$ and $\mathrm{AR}(+)$, and basal tumors were ER(-) and AR(-). Details of the breast specimens (normal-tumor, non-basal likebasal like, basal-luminal and ER (+)/ER (-)) available from GEO database were used in the supervised class prediction with a binary tree algorithm [26]. The common genes between the re-analyzed microarray studies and the meta-gene-lists were combined with respect to gene symbols (perl source codes are available upon request).

\section{Clinical Samples}

Primary tumor samples and matched non-tumor breast tissues were obtained from patients $(\mathrm{n}=10)$ during surgery and immediately snap-frozen in liquid nitrogen and stored at $-80^{\circ} \mathrm{C}$ until RNA extraction. The frozen tissue samples were sectioned and mounted on glass slides. The slides were stained with hematoxylin and eosin for histopathological examinations. Only those tumor samples with more than $90 \%$ of tumor cells and matched tissue pairs with normal histological examination were included in this study. These frozen tissues were cut into $5-\mu \mathrm{m}$ thick sections and used for RNA isolation and cDNA synthesis. All the tumor samples had been classified as infiltrating ductal carcinoma. The use of the tissue material in this project was approved by the Research Ethics Committee of Ankara Numune Research and Teaching Hospital and consents were obtained in accordance with the Helsinki Declaration.

\section{RNA extraction and CDNA synthesis}

The frozen breast specimens were put into Trizol reagent (AppliChem, Darmstadt, Germany), disrupted with a homogenizer and total RNA was isolated according to the manufacturer's instructions. Genomic DNA contaminations were removed by on-column DNasel treatment (Macharel Nagel, Duren, Germany). The concentration of the isolated RNA and the ratio of absorbance at $260 \mathrm{~nm}$ to $280 \mathrm{~nm}$ were measured with the NanoDrop ND-1000 spectrophotometer (NanoDrop Technologies, Montchanin, DE, USA) in triplicate.

First-strand cDNA was synthesized from $1 \mu \mathrm{g}$ total RNA using oligo(dT) primers using Revert Aid First strand cDNA synthesis kit according to the manufacturer's instructions (Fermentas, MD, USA). The cDNA was diluted at a ratio of 1:5 before being used as a PCR template and stored at $-20^{\circ} \mathrm{C}$ until further use.

\section{Real-Time quantitative RT-PCR}

Real-time qRT-PCR analysis was performed using genespecific primer pairs (Additional file 3). Real-time qRTPCR was performed on the BioRad iCycler Instrument (BioRad Laboratories, Hercules, CA, USA). The amplification mixtures contained $1.0 \mu \mathrm{l}$ of 1:5-diluted cDNA template, $6.25 \mu$ l SYBR Green PCR Master Mix Buffer, and 10 pmol of forward and reverse primers in a total volume of $12.5 \mu \mathrm{l}$. Cycling conditions were as follows: an initial incubation of $95^{\circ} \mathrm{C}$ for $5 \mathrm{~min}$ and then 45 cycles of $95^{\circ} \mathrm{C}$ for $30 \mathrm{~s}$ and $60^{\circ} \mathrm{C}$ for $30 \mathrm{~s}$ during which the fluorescence data were collected. To verify that the used primer pair produced only a single product, a dissociation protocol was added after thermocycling, determining dissociation of the PCR products from $55^{\circ} \mathrm{C}$ to $95^{\circ} \mathrm{C}$. Tumor and matched normal samples were always analyzed in the same run to exclude between-run variations and each sample was studied in duplicate. A no-template control of nuclease-free water was included in each run. An initial set of randomly selected genes from the DN list was used for real-time qRT-PCR validation studies. RAD21, GSN, COX6C, MAF, SFRP1, SPTNB1, GSPT1, NME1, PTTG1 but not MAF were also present in the LN list. Furthermore, seven other genes with potential predictive power for tumor subtype classification were studied by real-time qRT-PCR. These genes included FN1, ID4, EGFR, ADAMTS1, ATF3, IGFBPG, and PRNP. The geometrical mean of ACTB, TBP and SDHA1 gene expression values were used as internal control for relative gene expression quantitation [29]. Primer sequences and accession numbers of these genes were given in Additional file 3. The mean expression values obtained in resampling metaanalysis runs were used as a measure for comparing with the fold-change results obtained from the real-time qRTPCR validation studies; a Pearson correlation coefficient was also calculated $\left(\right.$ Matlab $\left.^{\circledR}\right)$.

\section{Results}

Correlation of Sorlie and Zhao Datasets

Combining the datasets in meta-analysis requires that they have similar expressions, both in magnitude and individual variability. To assess whether the Sorlie and Zhao datasets were correlated, a Pearson's correlation coefficient was calculated between the mean expression values of the ductal or lobular samples from each dataset, respectively before and after performing t-tests (Figure 2). Even before the removal of IMAGE clones showing significant differences between the studies, the mean expression values of ductal samples from Sorlie were highly correlated with those from Zhao; and a similar result was observed for the lobular samples $(r=0.8329$ and 0.8233 , 
A

Ductal $r=0.9389$

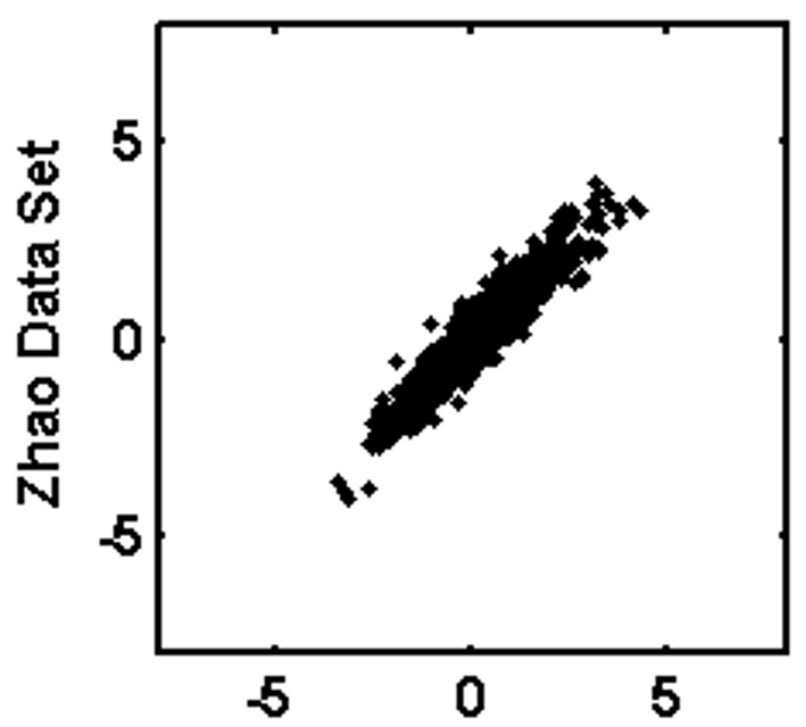

Lobular $r=0.8465$

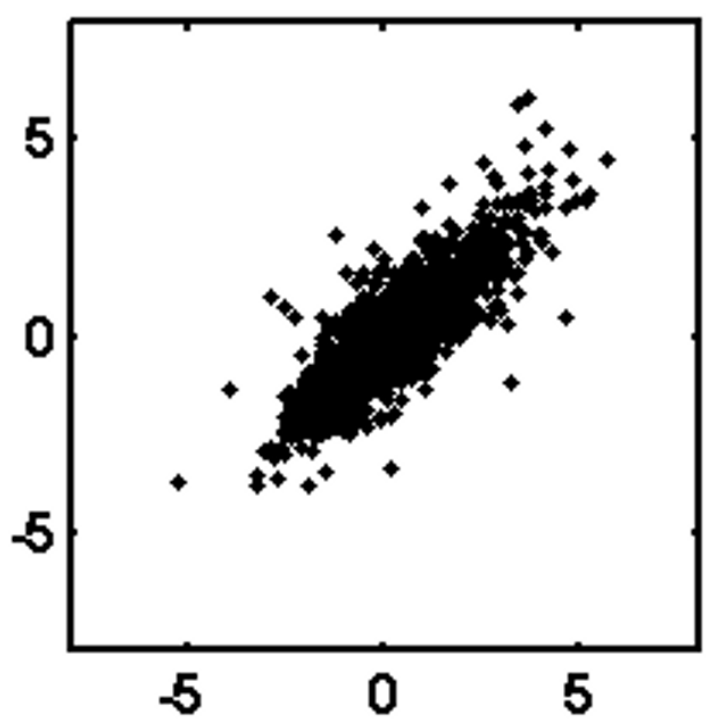

Sorlie Data Set

Figure 2

Pearson correlation coefficients (r) between Sorlie and Zhao datasets. Correlation plots between datasets after differentially expressed IMAGE clones were filtered out based on t-tests. (A) Correlation between mean expression values of ductal samples $(p<0.05)$. (B) Correlation between mean expression values of lobular samples $(p<0.05)$.

respectively). After filtering out the differentially expressed IMAGE clones, the correlations between the aforementioned datasets increased to 0.9389 and 0.8465 for the ductal and lobular samples, respectively. These results ensured that there was significant correlation between the Sorlie and Zhao datasets although they were based on independent tumor and normal samples.

\section{Distribution statistics for generation of meta-lists}

In this report, we used global-median normalized and filtered datasets since they minimized the number of manipulations performed during gathering of the metadata (see Additional file 4). Accordingly, assessment of significance was based on p-values obtained from the Kolmogorov-Smirnov analysis between test and random distributions ( $p t$ and $p r 1$, respectively) of a gene in the metadata. For example, the GSN gene had a highly significant differential expression between ductal and normal samples as evidenced by the highly skewed distribution towards lower p-values whereas the RAP2A gene exhibited a uniform distribution of p-values (Figures 3A, B and 3C, $\mathrm{D}$, respectively).

\section{Effects of resampling on estimates of expression and differentially expressed gene number}

We tested the effect of sample size and number of iterations on the estimation of mean expression level and the number of differentially expressed genes. For each run performed with a different sample size, the change in grand mean of expression (i.e., mean expression of all IMAGE clones) as well as the number of differentially expressed IMAGE clones were plotted with respect to the increasing number of iterations (Figure 4). As the number of iterations increased, the grand mean became more stabilized. Expectedly, the magnitude of change in mean values asymptotically decreased as the number of iteration and sampling size increased (Figure 4A and $4 \mathrm{C}$ ). On the other hand, the number of genes stated as significant increased as a function of the number of iterations and sampling size (Figure 4B, 4D). Significant IMAGE clones made up more than $70 \%$ of all analyzed genes at sampling size 6 with the highest iteration in ductal vs. normal analysis whereas the same set-up resulted in only $20 \%$ significant IMAGE clones in ductal vs. lobular analysis. 


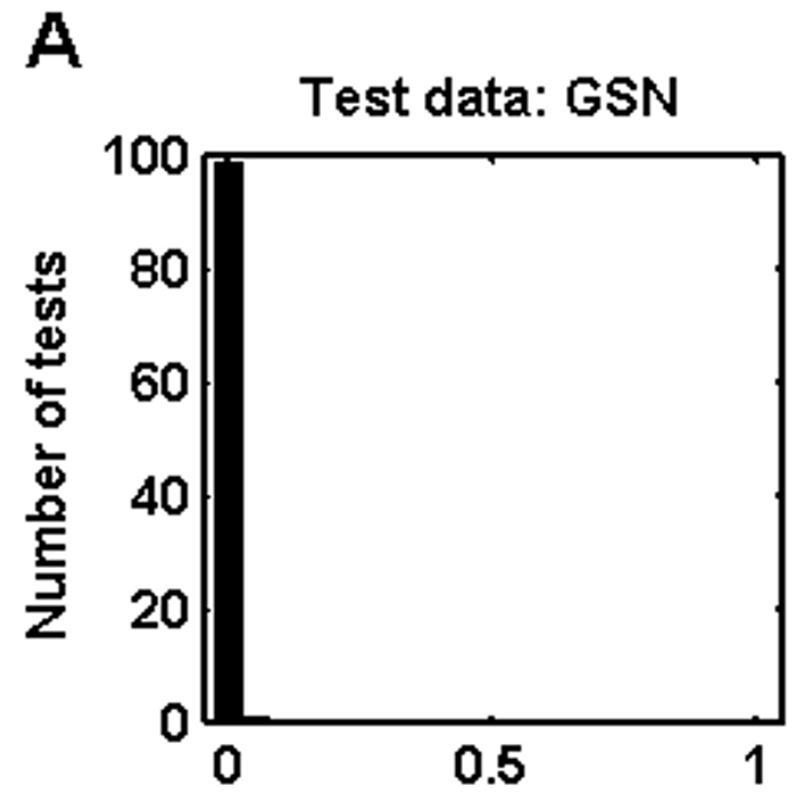

B

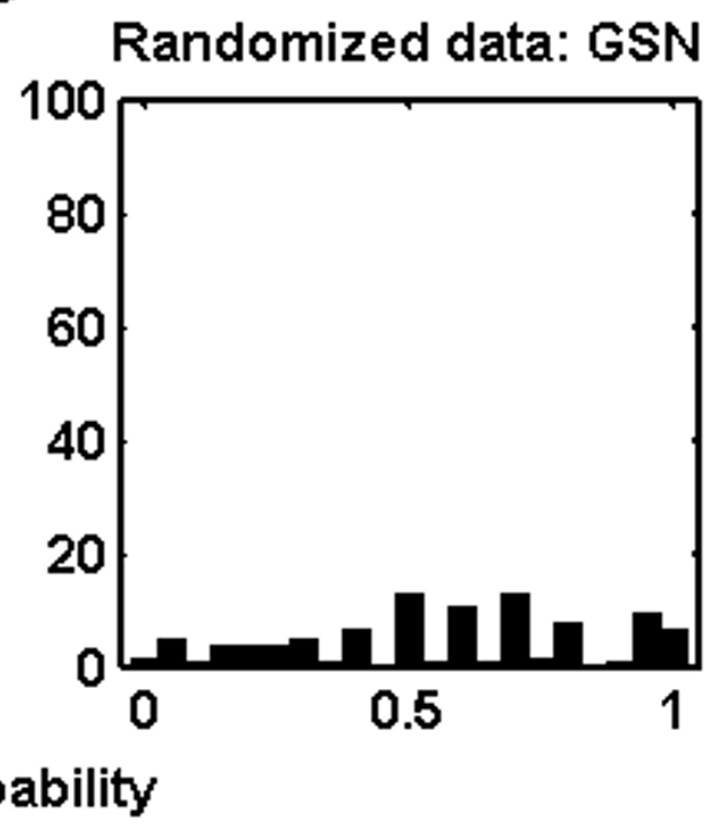

C

\section{D}

Probability

Test data: RAP2A

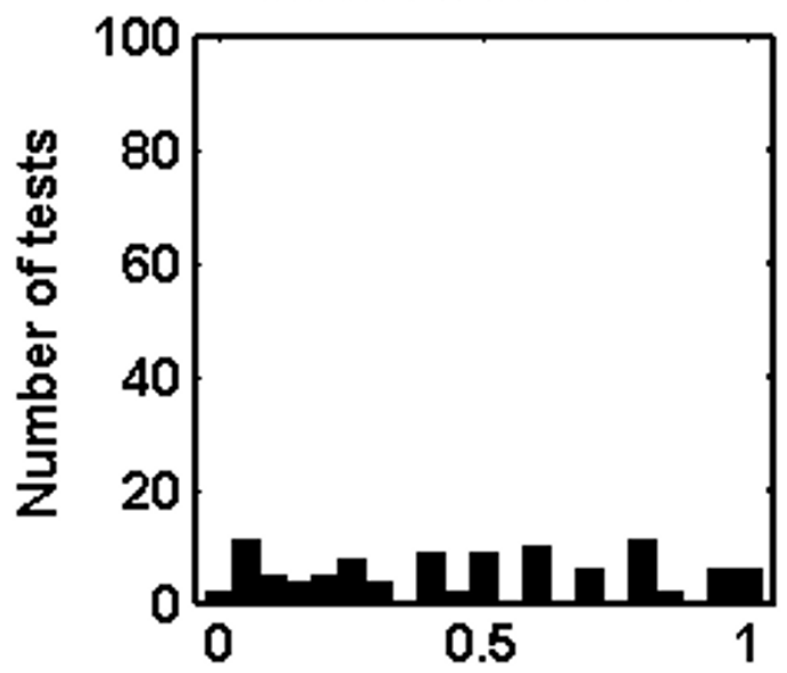

Randomized data: RAP2A

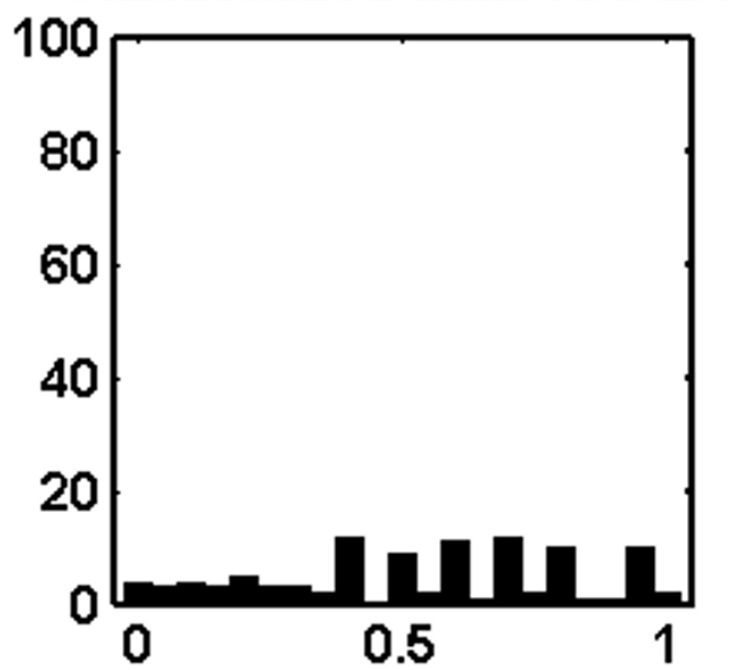

Probability

Figure 3

Examples for probability distributions of Wilcoxon rank sum tests. Data were obtained where resampling size, $n$, equaled to 6 (I00 iterations). Assessment of significance was based on p-values obtained from the Kolmogorov-Smirnov test between test and random distributions ( $p t$ and $p r l$, respectively). (A, C) For test data, GSN gene had a highly significant differential expression (significant at $100 \%$ of iterations, $p=0.00$ ) between ductal and normal samples whereas RAP2A gene did not (significant at $5 \%$ of iterations, $p=0.98$ ). (B, D) Probability values of both GSN and RAP2A, obtained from randomized data, were uniformly distributed. GSN; IMAGE: 2I4990 and RAP2A; IMAGE:36684. 


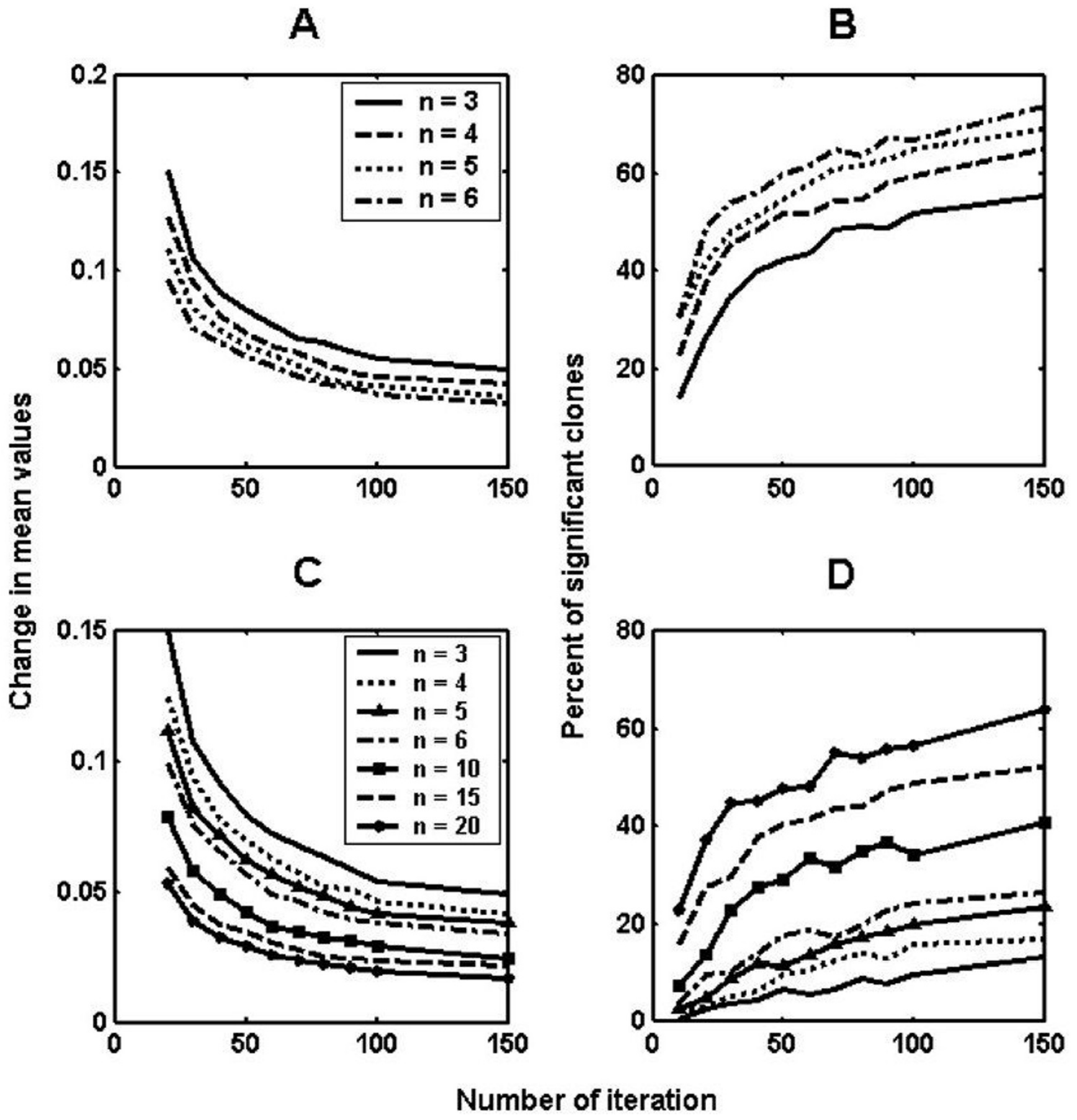

Figure 4

Effect of change in sample size and number of iterations on mean expression values and number of significant IMAGE clones. For each of the runs performed with different sample sizes ( $\mathrm{n})$, the change in the mean expression value (A, $C)$ and the number of IMAGE clones that were stated as differentially expressed (B, D) were plotted with respect to the increasing number of iterations. $A$ and $B$ refer to the results of ductal vs. normal analysis whereas $C$ and $D$ show the results of ductal vs. lobular analysis. 
It is reasonable to assume that use of a single sample size and iteration number may not be adequate to understand the variability among the tumor samples (Figure 4). It might instead be beneficial to consider all of the information gathered from the individual runs. Accordingly, the significant gene lists reported in this study were obtained by taking only those IMAGE clones that were assigned as significant in a given set of all resampling analyses performed $(90 \%$ or more for ductal-normal, DN; and lobular-normal, LN; and 80\% or more for ductal-lobular, DL comparisons) in an effort to minimize the effects of sampling size and iteration number on p-values.

\section{Characteristics of differentially expressed meta-gene lists} Differentially-expressed gene lists for DN and LN contained 298 (282 genes) and 216 (202 genes) IMAGE clones, respectively (see Additional files 5 and 6). On the other hand, there were only 66 (65 genes) differentially expressed IMAGE clones between the ductal and lobular (DL) datasets for $80 \%$ criteria (see Additional file 7 ). The size of these lists was dependent on the False Discovery Rate (FDR) input value (herein set to 0.01 ) or the percentage of resampling runs considered for significance (i.e., $90 \%$ or $80 \%$ ). In order to obtain a larger number of genes for DL analysis, the significance percentage value was set to 80 .

The same resampling procedures were also performed on the individual datasets, Sorlie and Zhao, separately. Compared to our meta-analysis these separate analyses together could provide $91 \%$ of IMAGE clones that were present in the significant DN list and LN list and 68\% of the IMAGE clones of the DL list. However neither of the studies could supply $9 \%$ of the IMAGE clones of the DN and LN list and 32\% of the DL list (90\% cut-off), each of which corresponds to a novel contribution by our meta- analysis (see Additional file 8 for meta-analysis specific gene lists).

We also compared the final DL significant gene list with the list of 52 genes reported by Zhao et al. [2]. The DL list shared CDH1, AOC3, FADS2, SORBS1, ALDH1A1, LPL, ANXA1 and AKR1C1 with that of Zhao et al. [2]. However, our analysis did not assign reasonable significance to the F11 and VWF genes according to the set cut-off criteria $(80 \%)$. The remaining genes in the Zhao gene list were not encountered since they were not included in the combined dataset used in the present meta-analysis. Metaanalysis of these two datasets provided a total of 36 significant genes not previously reported by Zhao et al and when either dataset is analyzed individually (see Additional file 7).

\section{Validation of tumor vs. normal meta-gene lists by independent microarray datasets}

Recent meta-analysis studies identified common cancer signatures by combining microarray datasets from different tissues for increasing accuracy of tumor vs. normal class prediction [30,31]. In this study, we focused on extracting a stable tumor molecular signature based on two of the existing breast cancer studies that contain microarray data on normal, IDC, and ILC tissue samples. We also have validated the predictive power of the metagene lists obtained through the resampling-based metaanalysis using three additional breast cancer datasets, which contain microarray data on 3 or more samples of normal and tumor breast tissues (Table 1) [5,7,8]. Accordingly, subsets of genes from $\mathrm{DN}$ and $\mathrm{LN}$ meta-gene lists were able to predict the tumor vs. normal classes with high accuracies, ranging from 80 to $100 \%$ (Table 1 ). Strikingly, correlation between expression values obtained from significant discriminators from each of the three

Table I: Summary of GEO breast cancer microarray datasets and results of class prediction analysis for the meta-gene lists, DN (Ductal/Normal) and LN (Lobular/Normal).

\begin{tabular}{|c|c|c|c|c|c|c|c|c|}
\hline \multirow[t]{3}{*}{ Study GEO ID } & \multicolumn{2}{|c|}{ Class } & \multicolumn{6}{|c|}{ Meta gene-list } \\
\hline & & & \multicolumn{3}{|c|}{$\mathrm{DN}$} & \multicolumn{3}{|c|}{$\mathrm{LN}$} \\
\hline & $\mathrm{N}$ & $\mathrm{T}$ & $\begin{array}{c}\text { Accuracy } \\
(\%)\end{array}$ & Number of genes & $r_{\mathrm{DN}}$ & $\begin{array}{c}\text { Accuracy } \\
(\%)\end{array}$ & Number of genes & $r_{L N}$ \\
\hline Turashvili [5] GDS2635 & 10 & 10 & 93 & 57 & 0.85 & 80 & 49 & 0.87 \\
\hline Richardson [7] GDS2250 & 7 & 40 & 100 & 145 & 0.86 & 100 & 96 & 0.78 \\
\hline Karnoub [8] GSE8977 & 15 & 7 & 95.5 & 109 & 0.72 & 95.5 & 89 & 0.81 \\
\hline
\end{tabular}

Normal $(\mathrm{N})$ and tumor $(\mathrm{T})$ sample sizes, accuracy of prediction from binary tree algorithm (\% accuracy), and the number of genes in classifier (number of genes) were shown for each study, separately. Correlation ( $r D N, r L N)$ of the classifier expression from each study with the DN and LN meta-gene expressions were also indicated (Pearson correlation, Minitab $\left.{ }^{\circledR} ; p^{2} 0.00 \mathrm{I}\right)$. 
normal/tumor datasets and those from the meta-analysis was high (Table 1). This indicated that the DN and LN lists harbored a robust expression profile for the breast tumors when compared with normal breast tissue.

\section{Prediction of tumor-subtypes}

We extracted a small, highly correlated classifier gene subset, which was commonly detected among the three microarray studies and the meta-analysis, to identify a more conservative gene set differentially expressed between tumor and normal cells (Additional file 9). Twenty-eight genes from the DN or LN meta-gene lists intersected with the three other microarray datasets (GDS2635, GDS2250, and GD1329); 17 of which were differentially expressed between basal vs. non-basal and/ or ER status (Additional file 9). For example, ADAMTS1, ATF3, IGFBP6, PRNP, EGFR, FN1, ID4, SPTBN1, and $S F R P 1$ genes from the DN list were found to significantly different in expression between nonbasal-like vs. basallike tumors as well as basal and luminal subtypes of the breast tumors $(\mathrm{p}<0.05)$. All of the above genes except FN1 were found to be significantly associated with the tumor ER status ( $\mathrm{p}<0.05$; Additional file 9).

\section{Validation of ductal vs. lobular meta-gene list}

Comparison of fold-change values of the DL meta-gene list consisting of 65 genes with that of the Turashvili's DL list (GDS2635) resulted in a high degree of correlation ( $r$ $=0.53 ; \mathrm{p}<0.001)$, suggesting that the direction and magnitude of expression change between the IDC and ILC samples were largely consistent between data from different microarray experiments. Furthermore, we combined published expression data from IDC and ILC samples from experiments performed by Bertucci et al [32] with the meta-analysis results (Additional File 7). Some of the members of the 65 meta-gene list were consistently downor up-regulated also in the Turashvili and Bertucci datasets (i.e., down-regulated ALDH1A1 and RBP4 in IDC; and upregulated $C D H 1$ and TFAP2A in IDC). Protein expression levels of these four genes were investigated using the Human Protein Atlas, a public resource for immunohistochemistry (IH) of normal and pathological human tissues http://www.proteinatlas.org/. IH data were available for CDH1, TFAP2A, and RBP4 proteins; and only data from antibodies exhibiting differential expression among breast tumors were reported herein. Accordingly, 2 out of 3 ILC samples exhibited moderate to strong signals for RBP4 (Antibody CAB00455) whereas 7 out of 9 IDC samples were either negative or had weak staining. CDH1 data in the Protein Atlas database was not very informative since the number of ILC samples were limited, but a moderate signal was detected for the ILC sample whereas 5 out of 6 IDC samples expressed CDH1 strongly (Antibody CAB000087). Similarly, TFAP2A was weakly or moderately expressed in the two ILC samples examined whereas a moderate to strong staining was observed in 5 of the 9 IDC samples. Although sample size in the ILC samples in the Human Protein Atlas database was limited, there was a corresponding trend between the mRNA levels reported by the present study and the protein level assessment obtained from the Human Protein Atlas. Future studies should include testing of the genes extracted by metaanalysis using protein level studies such as Western blotting or immunohistochemistry on a large set of IDC and ILC samples to confirm their predictive power.

\section{Validation of meta-analysis by real time qRT-PCR}

We first selected nine genes that were found to be differentially expressed in both the DN and LN lists (except $M A F$ ) from the meta-gene list for validation of the metaanalysis. Expression profiles of these genes were tested in independent paired IDC breast tumor and non-tumor tissue samples through real time qRT-PCR. Our results were consistent with those of the meta-analysis such that GSN, SPTBN1, SFRP1 and MAF were down-regulated in most tumor samples with respect to their matched non-tumor samples whereas COX6C, RAD21, GSPT1, NME1 and PTTG1 were up-regulated (Figure 5). Additionally we selected seven other genes, ATF3, ADAMTS1, EGFR, $P R N P$, IGFBP6, ID4 and FN1, found to be differentially expressed according to tumor subtype and ER+/ER- classification from the tumor-specific differentially expressed gene-set. All except FN1 were found to be down-regulated in tumor samples with respect to their normal counterparts. The meta-analysis results were supported by the real-time qRT-PCR experiments since all tested genes exhibited differences between matched normal and tumor samples in the same direction as expected by the metaanalysis (Pearson correlation coefficient, $\mathrm{r}=0.78, \mathrm{p}=$ $0.001)$.

Among the genes we used for validation through real time qRT-PCR, ID4 was the gene found to be differentially expressed between DN only by meta-analysis rather than each study alone.

\section{Discussion}

Microarrays allow high-throughput analysis of expression for thousands of genes and provide valuable information for tumor studies. For example, individual microarray studies have identified differentially expressed gene lists for distinguishing breast cancer subtypes and normal breast tissue $[5,6,8,9]$. Meta-analysis, on the other hand, might increase the knowledge by gathering and processing individual microarray datasets.

In the present study, we provided highly stable lists of differentially expressed genes based on meta-analysis of two breast cancer datasets [1,2]. We have used a resamplingbased strategy in which the effects of number of iterations 


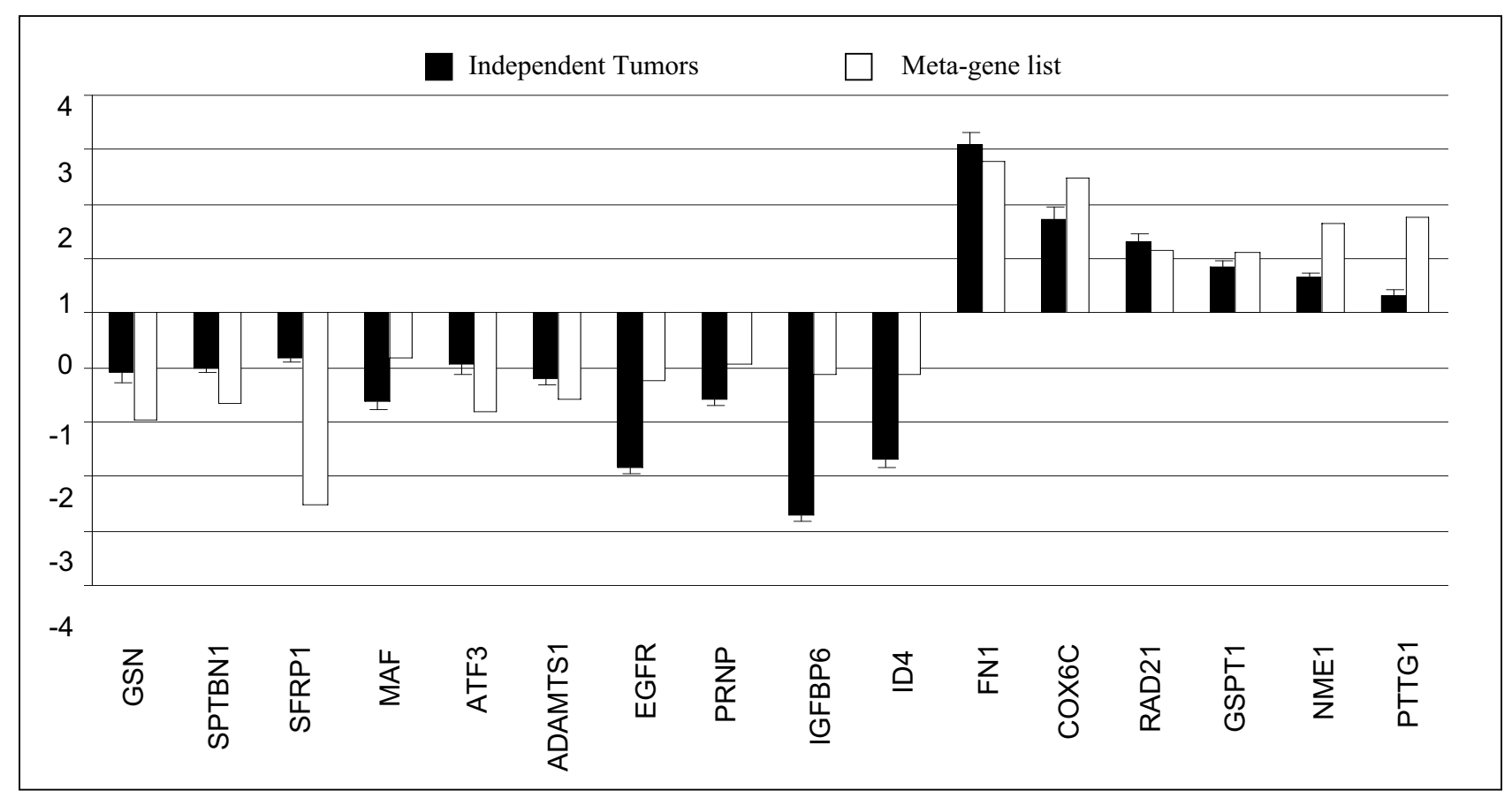

\section{Figure 5}

Validation of meta-analysis results by real-time qRT-PCR. Sixteen genes were selected from the ductal-normal (DN) significant meta-gene list for real-time qRT-PCR. Solid black bars refer to mean expression values $( \pm$ SEM) of I0 independent IDC breast tumors normalized to their non-tumor pairs. White bars refer to the mean expression values from the combined meta-gene list.

and sample size were minimized by using a voting scheme in which each IMAGE clone, at each run, was voted as either significantly- or non-differentially expressed and the significant counts then were added up. A percentage value was obtained by dividing the number of significant votes by the total number of votes and a threshold of $80-$ $90 \%$ for each IMAGE clone was chosen as a cut-off value for this meta-analysis. The meta-analysis was able to report multiple genes (i.e., 29, 21, and 6 genes for DN, LN, and DL, respectively) which neither dataset could report when analyzed individually.

Sample size greatly influences the reproducibility of the significant gene lists, such that the lower the sample size the less stable the gene lists become [19]. In addition, Qui et al. [18] have shown that the stability of genes identified as differentially expressed varies: some genes are consistently stable whereas others are not, independent of the statistical methodology used. Along these considerations, our voting scheme provided an advantage for extracting highly stable gene lists.

Different statistical methods are available for assessing differential expression. Among these, non-parametric tests allow for comparison of low sample size and distri- bution-independent comparisons. Our choice of ranksum test was based on this idea; similarly, previous studies reported the use of Kolmogorov-Smirnov test statistics to compare the reference and sample distributions in the context of Gene Ontologies [33]. We used a KolmogorovSmirnov test statistic for comparison of test and random distributions of p-values obtained from rank sum tests. In generating random datasets, we applied a gene-wise permutation algorithm that preserved the expression level information. Based on gene-wise permutations, a set of probability values that compare the actual and randomized distributions allowed for the assessment of the significance of the difference between groups tested using the Kolmogorov-Smirnov tests.

Different studies can be normalized and directly compared to each other in meta-analysis. Our comparisons ensured that there was a significant correlation between the Sorlie and Zhao datasets although these studies were based on independent tumor and normal samples; and the experimental procedures (e.g., amplification of RNA) also varied considerably between the two studies. Median rank scores [16] or quantile discretization algorithms have frequently been used to transform gene expression values from different studies to a common numerical range [17]. 
Since the global median-normalized and quantile-normalized data correlated well (see Additional file 4), we have used the former normalization method, with the least number of data manipulation steps, before combining these two datasets.

Due to the large number of comparisons involved in microarray data analysis, it is important to take into account the false positive error rate and control it for the number of tests performed. FDR is a well-known methodology for multiple-test correction; its estimation relies on calculation of the number of false positives in a randomly permuted set of experiments [34]. Therefore, we made comparisons between randomly shuffled datasets to obtain an estimate of FDR; and kept the value of FDR low (\% 0.01) to reduce the number of false positives.

Invasive breast tumors comprise 18 different histological types [24], most of which are classified as invasive ductal carcinoma not otherwise specified (IDC NOS). ILC, on the other hand, makes about $10-15 \%$ of all breast tumors and it is histologically characterized by uniform tumor cells arranged in single-files or concentrically localized around ducts [35]. ILC exhibit heterogeneity just like IDC; and a high-grade aggressive form of ILC known as pleomorphic lobular carcinoma (PLC) exists [36]. Bertucci et al. [32] reported that IDC and ILC were histologically and genomically distinguishable from each other among the ER(+) grade II invasive breast tumors. Furthermore, ILC molecular subtypes were reported to include the typical and IDC-like ILCs, yet the CDH1 mutation and/or underexpression was common but not universal to ILCs in general [35]. Low-grade breast tumors were generally characterized by $\mathrm{ER}(+), \mathrm{PR}(+)$ and with limited genomic aberrations whereas high grade tumors were generally ER(-) and PR(-) and had complex karyotypic changes. However, molecular differences among subtypes may not surpass the differences between any tumor cell and the normal since the degree of genomic stability in normal cells would be relatively higher.

The other three studies presenting data on ILC and IDC, Turashvili et al. [5], Sorlie et al. [1] and Zhao et al. [2] have used a more diverse selection of tumor samples. Although IDC and ILC have distinctive clinical and pathological characteristics and differ in their ER status and metastatic behaviors [22], meta-analysis of Zhao and Sorlie datasets indicated that a small number of genes distinguished between the expression profiles of IDC and ILC patients. On the other hand, the number of genes that were differentially expressed between normal and IDC or normal and ILC samples was much greater. Indeed, Turashvili et al. [5] has also reported only 28 genes that were significantly differentially expressed between IDC and ILC samples, which were extracted using laser-dissection, a more recent methodology allowing for precise collection of a given cell population. These findings suggest that the degree of molecular differences between IDC and ILC are indeed smaller than those between the tumor and normal classes.

Comparisons between the meta-analysis and the Turashvili and Bertucci studies pointed out to CHD1, TFAP2A, RBP4, and ALDH1A1 genes as commonly modulated. Indeed, $C D H 1$ is one of the best-studied discriminators for ductal/lobular breast cancer specimens in the literature by immunohistochemistry and at the genomic level. In breast cancer, reduced $\mathrm{CDH} 1$ expression has been found in $50 \%$ of invasive ductal carcinomas, whereas $\mathrm{CDH} 1$ expression was almost always absent in infiltrating lobular carcinoma (ILC) $[1,2,5,32,37,38]$. TFAP2A was shown to be highly expressed in ductal tumor cells while normal cells expressed TFAP2A in the inner glandular cell layer [39]. On the other hand, nuclear TFAP2 expression was shown to be higher in lobular than ductal breast carcinomas [40]. There is no report on RBP4 in the literature in connection with ductal vs. lobular breast cancer distinction while ALDH1A1 protein levels were shown to exhibit differences among the ductal carcinoma patients [41]. The candidates identified in the meta-analysis then are likely to be discriminatory at the mRNA level rather than the protein level since protein localization and variability in intensity might make the ductal vs. lobular tissue discrimination less clear. Therefore, it is of paramount importance that future confirmatory studies include use of independent ILC and IDC samples for quantitative expression profiling of the selected candidate genes.

On the other hand, analyses of Sorlie, Zhao, and Turashvili data showed that tumor cells were remarkably distinct from their respective normals in their transcription profiles implicating that whatever the subtype structure underneath, most of the variability among samples was due to changes during tumorigenesis. Accordingly, the idea that genes discriminating tumor from normal in a stable manner also may have information on the state of the tumorigenesis is a valid one.

Breast tumor subtype classification remains a complicated issue due to difficulties associated with the presence of multiple interacting factors such as the presence or absence of node-filtration, ER-positivity, metastatic potential, different degrees of genomic instability, and tumor cell origin. For example, basal like cancers have distinct molecular expression profiles and histological differences when compared with the luminal type [42]. Nielsen et al. [43] have categorized basal like breast cancer tumors as having variable levels of expression of one of the three stem/basal markers, namely CK5/6, EGFR, and c-kit. Luminal cell markers, on the other hand, include CK8, 
CK18, CK19, mostly characteristic of glandular and/or lobular epithelial cells [44]. However, both the basal and luminar histochemical markers may exist simultaneously suggesting that breast cancer is rather a heterogeneous tissue [45]. It is also evident that tumors with a triple negative status (ER-, PR-, HER2-) are more likely to belong to the basal type $[43,46]$. In general, gene expression studies associated the basal-like breast tumors with high proliferative abilities and thus having a worse prognosis when compared with the luminal subtype of breast cancers $[1,47]$. Thus identification of genes best classifying breast cancer into intrinsic molecular subtypes like luminal, HER2+/ER- and basal-like also allows determination of risk factors and likely prognosis for the patients. The importance of identification of these different subtypes is that they differ in clinical outcome and molecular subtype signatures thus help predict clinical outcome and response to therapy.

Differentially expressed genes between tumor and normal states (DN and LN) also keep information about intrinsic subtypes. Accordingly, meta-analysis identified ATF3, ADAMTS1, EGFR, PRNP, IGFBP6, ID4, SFRP1, SPTBN1, and FN1 with ability to classify tumors into basal and luminal subclasses. Additionally most of them accurately differentiated ER(+) and ER(-) tumors (Additional file 9).

Among those genes, ID4 was found to be a novel tumor suppressor gene in normal human breast tissues and epigenetically silenced in breast cancer cell lines and primary breast tumors $[48,49]$. As supporting information for our data, de Candia et al. suggested that the expression of ID4 in the mammary duct epithelium may be regulated by estrogen depending on the differential expression pattern of ID4 in ER(+) and ER(-) breast tumors [50]. SFRP1 on the other hand is a frizzled-related protein that plays a role in a variety of cellular processes, including control of cell polarity, cell fate determination, and malignant transformation. In previous studies, loss of SFRP1 was found to be associated with cancer progression and poor prognosis in breast cancer [51,52]. EGFR is known to be a positive immunohistochemical marker for basal-like breast cancers and it was shown to accurately identify basal-like tumors from microarray data with potential therapeutic implications [53,54]. Activating transcription factor 3 (ATF3) is a member of the ATF/cyclic AMP response element-binding family of transcription factors. It was shown to enhance apoptosis in the untransformed mammary epithelial cells while protecting the aggressive cells and enhancing cell motility. Array analyses indicated that ATF3 upregulated the expression of several genes in the tumor necrosis factor pathway in the untransformed mammary epithelial cells. However, the expression of sev- eral genes implicated in tumor metastasis including fibronectin (FN1) was upregulated in aggressive cells. ATF3 was also shown to regulate the transcription of FN1, one of the genes obtained in the present study. ATF3 gene copy number was at least doubled in $80 \%$ of the breast tumors examined; protein levels also were elevated in close to $50 \%$ of these tumors [55].

Since the normal vs. tumor classification was strikingly distinct based on meta-analysis, and a gene-set with the capacity for breast cancer subtype classification, we further analyzed a set of normal matched tumors for selected genes from the meta-gene list using real-time qRT-PCR. The selected 16 significant genes were shown to have expression profiles similar to those found from the metaanalysis. Our findings also suggested that these genes could be used as predictors of tumor status regardless of the origin of the reference samples, i.e., a matched or pooled reference tissue. Since the number of samples used in qRT-PCR was relatively small, increasing the sample size may help generalize our results to a wider range of breast tumor samples.

There was a high level of correlation between fold changes obtained from the DL meta-genes and those from the Turashvili dataset, regardless of the different sample extraction methods used in each study (i.e., frozen sections and laser-dissection, respectively). The meta-gene list discriminating between ductal and lobular breast tumor samples at the mRNA level requires further confirmation at the protein level to better assess discriminatory power. Future validation studies might concentrate on whether meta-analysis specific genes also participate in prediction of level of prognosis and/or time to diseasefree survival.

\section{Conclusion}

In this study, meta-analysis of two independent comparable microarray data sets allowed us to provide genes that are able to discriminate IDC and ILC and normal mammary cells from the tumors that either study by itself was not able to identify. We also provided highly generalized and stable gene lists that could be used for prediction of tumor or normal status. The meta-gene list for tumor/normal comparison had a striking predictive ability based on comparisons made with three independent microarray datasets. The resampling approach proposed herein has the ability to detect a set of differentially expressed genes, with the least amount of within-group variability. This metaanalytic approach thus provides a method to combine two or more independent cancer data sets leading to the identification of differentially expressed gene sets for better understanding of cancer development and progression. 


\section{Abbreviations}

DL: Ductal and Lobular; DN: Ductal and Normal; FDR: False Discovery Rate; IDC: Invasive Ductal Carcinoma; ILC: Invasive Lobular Carcinoma; LN: Lobular and Normal; qRT-PCR: Quantitative Reverse Transcriptase Polymerase Chain Reaction; SMD: Stanford Microarray Database.

\section{Competing interests}

The authors declare that they have no competing interests.

\section{Authors' contributions}

IGY, BGD and OK originally conceptualized the metaanalysis method and application to breast cancer datasets, and wrote the manuscript. OK and SK developed the meta-analysis algorithm; SK contributed to manuscript writing. BGD and SK applied the algorithm to breast cancer datasets and generated figures. BDG performed all BRB-tool analyses and carried out expression studies. ARO and OK wrote algorithms for data extraction and compilation. $\mathrm{BB}$ carried out the surgical removal of the sample tissues and GE, the pathological assessment of the surgical tissue materials. IGY coordinated the study and participated in its design. All authors read and approved the final manuscript.

\section{Additional material}

\section{Additional file 1}

Complete list of common IMAGE clones. The data represents $4769 \mathrm{com}$ mon IMAGE clones from combined Sorlie and Zhao datasets from the study of Zhao et al. [2].

Click here for file

[http://www.biomedcentral.com/content/supplementary/14712407-8-396-S1.xls]

\section{Additional file 2}

Complete list of common IMAGE clones. The data represents $4769 \mathrm{com}$ mon IMAGE clones from combined Sorlie and Zhao datasets from the study of Sorlie et al. [1].

Click here for file

[http://www.biomedcentral.com/content/supplementary/1471-

2407-8-396-S2.xls]

\section{Additional file 3}

Genes used for real-time qRT-PCR analysis. Gene names, accession numbers and gene specific primer pairs used for real-time qRT-PCR analysis of the selected genes.

Click here for file

[http://www.biomedcentral.com/content/supplementary/14712407-8-396-S3.pdf]

\section{Additional file 4}

Correlation of global median and quantile normalized data. The figure shows the correlation of global median and quantile normalized data of ductal (D) and normal (N) tissue samples.

Click here for file

[http://www.biomedcentral.com/content/supplementary/14712407-8-396-S4.pdf]

\section{Additional file 5}

Gene set differentially expressed between ductal (D) and normal (N) breast tissue samples. The data provided represents the list of 298 IMAGE clones differentially expressed between ductal (D) and normal (N) samples with $90 \%$ significance.

Click here for file

[http://www.biomedcentral.com/content/supplementary/14712407-8-396-S5.xls]

\section{Additional file 6}

Gene set differentially expressed between lobular $(L)$ and normal $(N)$ breast tissue samples. The data provided represents the list of 216 IMAGE clones differentially expressed between lobular $(L)$ and normal (N) samples with $90 \%$ significance.

Click here for file

[http://www.biomedcentral.com/content/supplementary/14712407-8-396-S6.xls]

\section{Additional file 7}

Gene set differentially expressed between ductal (D) and lobular (L) breast tissue samples. The data provided represents the list of 66 IMAGE clones differentially expressed between ductal $(D)$ and lobular $(L)$ samples with $80 \%$ significance.

Click here for file

[http://www.biomedcentral.com/content/supplementary/14712407-8-396-S7.xls]

\section{Additional file 8}

List of meta-analysis specific genes. The file includes the list of genes differentially expressed between $D N, L N$, and DL samples.

Click here for file

[http://www.biomedcentral.com/content/supplementary/1471-

2407-8-396-S8.xls]

\section{Additional file 9}

Validation of meta-analysis gene lists by three independent microarray datasets. The file represents the gene lists obtained by comparing the $D N$ and $L N$ meta-gene list to the gene expression profiles of normal and breast tumor tissues from three independent microarray datasets. Click here for file [http://www.biomedcentral.com/content/supplementary/14712407-8-396-S9.xls]

\section{Acknowledgements}

This work was funded by a grant from the Scientific and Technical Research Council of Turkey (107TI8I) and supported by Bilkent University.

\section{References}

I. Sorlie T, Tibshirani R, Parker J, Hastie T, Marron JS, Nobel A, Deng S, Johnsen H, Pesich R, Geisler S, Demeter J, Perou CM, Lonning PE, Brown PO, Borresen-Dale AL, Bodstein D: Repeated observation of breast tumor subtypes in independent gene expression data sets. Proc Natl Acad Sci USA 2003, 1 00:8418-8423.

2. Zhao H, Langerod A, Ji Y, Nowels KW, Nesland JM, Tibshirani R, Bukholm IK, Karesen R, Botstein D, Borresen-Dale AL, Jeffrey SS: Different Gene Expression Patterns in Invasive Lobular and Ductal Carcinomas of the Breast. Mol Biol Cell 2004, I 5:2523-2536.

3. van 't Veer LJ, Dai $H$, Vijver MJ van de, He YD, Hart AA, Mao M, Peterse HL, Kooy K van der, Marton MJ, Witteveen AT, Schreiber G], Kerkhoven RM, Roberts C, Linsley PS, Bernards R, Friend SH: Gene 
expression profiling predicts clinical outcome of breast cancer. Nature 2002, 4I5(687I):530-536.

4. Farmer $P$, Bonnefoi $H$, Becette $V$, Tubiana-Hulin M, Fumoleau P, Larsimont D, Macgrogan G, Bergh J, Cameron D, Goldstein D, Duss S, Nicoulaz AL, Brisken C, Fiche M, Delorenzi M, Iggo R: Identification of molecular apocrine breast tumours by microarray analysis. Oncogene 2005, 24:4660-467I.

5. Turashvili G, Bouchal J, Baumforth K, Wei W, Dziechciarkova M, Ehrmann J, Klein J, Fridman E, Skarda J, Srovnal J, Hajduch M, Murray P, Kolar Z: Novel markers for differentiation of lobular and ductal invasive breast carcinomas by laser microdissection and microarray analysis. BMC Cancer 2007, 7:55.

6. Grigoriadis A, Mackay A, Reis-Filho JS, Steele D, Iseli C, Stevenson BJ, Jongeneel CV, Valgeirsson H, Fenwick K, Iravani M, Leao M, Simpson A], Strausberg RL, Jat PS, Ashworth A, Neville AM, O'Hare M]: Establishment of the epithelial-specific transcriptome of normal and malignant human breast cells based on MPSS and array expression data. Breast Cancer Res 2006, 8:R56.

7. Richardson AL, Wang ZC, De Nicolo A, Lu X, Brown M, Miron A, Liao X, Iglehart JD, Livingston DM, Ganesan S: $\mathbf{X}$ chromosomal abnormalities in basal-like human breast cancer. Cancer Cell 2006, 9:12I-132.

8. Karnoub AE, Dash AB, Vo AP, Sullivan A, Brooks MW, Bell GW, Richardson AL, Polyak K, Tubo R, Weinberg RA: Mesenchymal stem cells within tumor stroma promote breast cancer metastasis. Nature 2007, 449:557-563.

9. Tripathi A, King C, de la Morenas A, Perry VK, Burke B, Antoine GA, Hirsch EF, Kavanah M, Mendez J, Stone M, Gerry NP, Lenburg ME, Rosenberg CL: Gene expression abnormalities in histologically normal breast epithelium of breast cancer patients. Int J Cancer 2008, I22:1557-1566.

10. Smith DD, Saetrom P, Snøve O Jr, Lundberg C, Rivas GE, Glackin C, Larson GP: Meta-analysis of breast cancer microarray studies in conjunction with conserved cis-elements suggest patterns for coordinate regulation. BMC Bioinformatics 2008, 9:63.

11. Thomassen M, Tan Q, Kruse TA: Gene expression meta-analysis identifies chromosomal regions and candidate genes involved in breast cancer metastasis. Breast Cancer Res Treat 2009, I I 3(2):239-249.

12. Hu Z, Fan C, Oh DS, Marron JS, He X, Qaqish BF, Livasy C, Carey LA, Reynolds E, Dressler L, Nobel A, Parker J, Ewend MG, Sawyer LR, Wu J, Liu Y, Nanda R, Tretiakova M, Ruiz Orrico A, Dreher D, Palazzo JP, Perreard L, Nelson E, Mone M, Hansen H, Mullins M, Quackenbush JF, Ellis MJ, Olopade OI, Bernard PS, Perou CM: The molecular portraits of breast tumors are conserved across microarray platforms. BMC Genomics 2006, 7:96.

13. Moreau Y, Aerts S, De Moor B, De Strooper B, Dabrowski M: Comparison and meta-analysis of microarray data: from the bench to the computer desk. Trends Genet 2003, 19:570-577.

14. Rhodes DR, Barrette TR, Rubin MA, Ghosh D, Chinnaiyan AM: Meta-analysis of microarrays: interstudy validation of gene expression profiles reveals pathway dysregulation in prostate cancer. Cancer Res 2002, 62:4427-4433.

15. Choi JK, Yu U, Kim S, Yoo OJ: Combining multiple microarray studies and modeling interstudy variation. Bioinformatics 2003 , I 9(Suppl I):i84-90.

16. Toedling J, Spang R: Assessment of Five Microarray Experiments on Gene Expression Profiling of Breast Cancer. Poster Presentation RECOMB 2003 [http://citeseer.ist.psu.edu/6/1350.html].

17. Warnat $\mathrm{P}$, Eils R, Brors $B$ : Cross-platform analysis of cancer microarray data improves gene expression based classification of phenotypes. BMC Bioinformatics 2005, 6:265.

18. Qiu X, Xiao Y, Gordon A, Yakovlev A: Assessing stability of gene selection in microarray data analysis. BMC Bioinformatics 2006, 7:50.

19. Pavlidis P, Qin J, Arango V, Mann JJ, Sibille E: Using the gene ontology for microarray data mining: a comparison of methods and application to age effects in human prefrontal cortex. Neurochem Res 2004, 29:12 I3-1222.

20. Choi JK, Choi JY, Kim DG, Choi DW, Kim BY, Lee KH, Yeom YI, Yoo $\mathrm{HS}$, Yoo OJ, Kim S: Integrative analysis of multiple gene expression profiles applied to liver cancer study. FEBS Lett 2004, 565:93-100.

21. Grutzmann R, Boriss H, Ammerpohl O, Luttges J, Kalthoff H, Schackert HK, Kloppel G, Saeger HD, Pilarsky C: Meta-analysis of micro- array data on pancreatic cancer defines a set of commonly dysregulated genes. Oncogene 2005, 24:5079-5088.

22. Arpino G, Bardou VJ, Clark GM, Elledge RM: Infiltrating lobular carcinoma of the breast: tumor characteristics and clinical outcome. Breast Cancer Res 2004, 6:R I49-I56.

23. Korkola JE, DeVries S, Fridlyand J, Hwang ES, Estep AL, Chen YY, Chew KL, Dairkee SH, Jensen RM, Waldman FM: Differentiation of lobular versus ductal breast carcinomas by expression microarray analysis. Cancer Res 2003, 63:7167-7I75.

24. Weigelt B, Horlings $H$, Kreike B, Hayes M, Hauptmann M, Wessels L, de Jong $D$, Vijver $M$ Van de, Veer LjV, Peterse J: Refinement of breast cancer classification by molecular characterization of histological special types. J Pathol 2008, 216:14I-150.

25. Li Cl, Malone KE, Porter PL, Weiss NS, Tang MT, Daling JR: Reproductive and anthropometric factors in relation to the risk of lobular and ductal breast carcinoma among women 65-79 years of age. Int J Cancer 2003, 107:647-65I

26. Biometric Research Branch [http://linus.nci.nih.gov/BRB-Array Tools.html]

27. Stanford Microarray Database [http://genome-www5.stan ford.edu/]

28. Gene Expression Omnibus [http://www.ncbi.nlm.nih.gov/geo/]

29. Pfaffl MW: A new mathematical model for relative quantification in real-time RT-PCR. Nucleic Acids Res 200I, 29:e45.

30. Rhodes DR, Yu J, Shanker K, Deshpande N, Varambally R, Ghosh D, Barrette T, Pandey A, Chinnaiyan AM: Large-scale meta-analysis of cancer microarray data identifies common transcriptional profiles of neoplastic transformation and progression. Proc Natl Acad Sci USA 2004, I 0 I:9309-93 I4.

31. Xu L, Geman D, Winslow RL: Large-scale integration of cancer microarray data identifies a robust common cancer signature. BMC Bioinformatics 2007, 8:275

32. Bertucci $F$, Orsetti $B$, Nègre $V$, Finetti $P$, Rougé $C$, Ahomadegbe JC, Bibeau F, Mathieu MC, Treilleux I, Jacquemier J, Ursule L, Martinec A, Wang Q, Bénard J, Puisieux A, Birnbaum D, Theillet C: Lobular and ductal carcinomas of the breast have distinct genomic and expression profiles. Oncogene 2008, 27:5359-5372.

33. Ben-Shaul $\mathrm{Y}$, Bergman $\mathrm{H}$, Soreq $\mathrm{H}$ : Identifying subtle interrelated changes in functional gene categories using continuous measures of gene expression. Bioinformatics 2005, 2 I : I I 29- I I 37.

34. Benjamini $Y$, Hochberg $Y$ : Controlling the false discovery rate: $\mathbf{A}$ practical and powerful approach to multiple testing. J Roy Statis Soc Ser 1995, 57:289-300.

35. Yoder BJ, Wilkinson EJ, Massoll NA: Molecular and morphologic distinctions between infiltrating ductal and lobular carcinoma of the breast. Breast J 2007, I 3: I72- 179.

36. Simpson PT, Reis-Filho JS, Lambros MB, Jones C, Steele D, Mackay A, Iravani M, Fenwick K, Dexter T, Jones A, Reid L, Da Silva L, Shin S], Hardisson D, Ashworth A, Schmitt FC, Palacios J, Lakhani SR: Molecular profiling pleomorphic lobular carcinomas of the breast: evidence for a common molecular genetic pathway with classic lobular carcinomas. J Pathol 2008, 2 I 5:23I-244.

37. Sarrió D, Moreno-Bueno G, Hardisson D, Sánchez-Estévez C, Guo M, Herman JG, Gamallo C, Esteller M, Palacios J: Epigenetic and genetic alterations of APC and CDHI genes in lobular breast cancer: relationships with abnormal E-cadherin and catenin expression and microsatellite instability. Int J Cancer 2003, 106:208-2I5.

38. Caldeira JR, Prando EC, Quevedo FC, Neto FA, Rainho CA, Rogatto SR: CDHI promoter hypermethylation and E-cadherin protein expression in infiltrating breast cancer. BMC Cancer 2006, 6:48.

39. Friedrichs $N$, Jäger R, Paggen E, Rudlowski C, Merkelbach-Bruse $S$, Schorle $H$, Buettner R: Distinct spatial expression patterns of AP-2alpha and AP-2gamma in non-neoplastic human breast and breast cancer. Mod Pathol 2005, 18:43I-438.

40. Pellikainen J, Kataja V, Ropponen K, Kellokoski J, Pietiläinen T, Böhm J, Eskelinen M, Kosma VM: Reduced nuclear expression of transcription factor AP-2 associates with aggressive breast cancer. Clin Cancer Res 2002, 8:3487-3495.

4I. Sládek NE: Aldehyde dehydrogenase-mediated cellular relative insensitivity to the oxazaphosphorines. Curr Pharm Des 1999, 5:607-625.

42. Fadare $O$, Tavassoli FA: The phenotypic spectrum of basal-like breast cancers: a critical appraisal. Adv Anat Pathol 2007, 14:358-373. 
43. Nielsen TO, Hsu FD, Jensen K, Cheang M, Karaca G, Hu Z, Hernandez-Boussard T, Livasy C, Cowan D, Dressler L, Akslen LA, Ragaz J, Gown AM, Gilks CB, Rijn M van de, Perou CM: Immunohistochemical and clinical characterization of the basal-like subtype of invasive breast carcinoma. Clin Cancer Res 2004, 10:5367-5374.

44. Abd El-Rehim DM, Pinder SE, Paish CE, Bell J, Blamey RW, Robertson JF, Nicholson RI, Ellis IO: Expression of luminal and basal cytokeratins in human breast carcinoma. J Pathol 2004, 203:66 I-67I.

45. Moriya T, Kasajima A, Ishida K, Kariya Y, Akahira J, Endoh M, Watanabe M, Sasano H: New trends of immunohistochemistry for making differential diagnosis of breast lesions. Med Mol Morphol 2006, 39:8-13.

46. Liu ZB, Liu GY, Yang WT, Di GH, Lu JS, Shen KW, Shen ZZ, Shao $Z M$, Wu J: Triple-negative breast cancer types exhibit a distinct poor clinical characteristic in lymph node-negative Chinese patients. Oncol Rep 2008, 20:987-994.

47. Sotiriou C, Neo SY, McShane LM, Korn EL, Long PM, Jazaeri A, Martiat $P$, Fox SB, Harris AL, Liu ET: Breast cancer classification and prognosis based on gene expression profiles from a population-based study. Proc Natl Acad Sci USA 2003, 100:10393-10398.

48. Noetzel E, Veeck J, Niederacher D, Galm O, Horn F, Hartmann A, Knüchel R, Dahl E: Promoter methylation-associated loss of ID4 expression is a marker of tumour recurrence in human breast cancer. BMC Cancer 2008, 8: 154 .

49. Umetani N, Mori T, Koyanagi K, Shinozaki M, Kim J, Giuliano AE, Hoon DS: Aberrant hypermethylation of ID4 gene promoter region increases risk of lymph node metastasis in TI breast cancer. Oncogene 2005, 24:472I-4727.

50. de Candia P, Akram M, Benezra R, Brogi E: Id4 messenger RNA and estrogen receptor expression: inverse correlation in human normal breast epithelium and carcinoma. Hum Pathol 2006, 37:1032-104I.

5I. Klopocki E, Kristiansen G, Wild PJ, Klaman I, Castanos-Velez E, Singer G, Stohr R, Simon R, Sauter G, Leibiger H, Essers L, Weber B, Hermann K, Rosenthal A, Hartmann A, Dahl E: Loss of SFRPI is associated with breast cancer progression and poor prognosis in early stage tumors. Int J Oncol 2004, 25:64I-649.

52. Kawano Y, Kypta R: Secreted antagonists of the Wnt signalling pathway. I Cell Sci 2003, I I 6:2627-2634.

53. Cheang MC, Voduc D, Bajdik C, Leung S, McKinney S, Chia SK, Perou CM, Nielsen TO: Basal-like breast cancer defined by five biomarkers has superior prognostic value than triple-negative phenotype. Clin Cancer Res 2008, 14:1368-1376.

54. Arnes JB, Bégin LR, Stefansson IM, Brunet JS, Nielsen TO, Foulkes WD, Akslen LA: Expression of EGFR in relation to BRCAI status, basal-like markers and prognosis in breast cancer. In J Clin Pathol 2008.

55. Yin X, Dewille JW, Hai T: A potential dichotomous role of ATF3, an adaptive-response gene, in cancer development. Oncogene 2008, 27:21।8-2I27.

\section{Pre-publication history}

The pre-publication history for this paper can be accessed here:

http://www.biomedcentral.com/1471-2407/8/396/pre pub
Publish with Biomed Central and every scientist can read your work free of charge

"BioMed Central will be the most significant development for disseminating the results of biomedical research in our lifetime. "

Sir Paul Nurse, Cancer Research UK

Your research papers will be:

- available free of charge to the entire biomedical community

- peer reviewed and published immediately upon acceptance

- cited in PubMed and archived on PubMed Central

- yours - you keep the copyright

Submit your manuscript here:

http://www.biomedcentral.com/info/publishing_adv.asp
BiolMedcentral 